\title{
Caracterização do Pasto de Capim-Buffel Diferido e da Dieta de Bovinos, Durante o Período Seco no Sertão de Pernambuco 1
}

\author{
Gladston Rafael de Arruda Santos ${ }^{2}$, Adriana Guim ${ }^{3}$, Mércia Virginia Ferreira dos Santos ${ }^{4}$, \\ Marcelo de Andrade Ferreira ${ }^{4}$, Mário de Andrade Lira ${ }^{4}$, José Carlos Batista Dubeux Júnior ${ }^{4}$, \\ Maria José da Silva 5
}

\begin{abstract}
RESUMO - Objetivou-se, neste experimento, quantificar a disponibilidade de massa seca e avaliar a composição botânica e bromatológica de pastagem de capim-buffel diferida e da dieta de bovinos, durante o período seco. Foram realizadas estimativas visuais para determinação da composição botânica e do corte de amostras, para determinação da disponibilidade da forragem, sendo os dados processados pelo programa BOTANAL. Três animais fistulados no esôfago foram utilizados para avaliar a qualidade e composição botânica da dieta selecionada. As médias foram comparadas pelo teste Tukey a 5\% de probabilidade, empregando-se o procedimento estatístico SAS. Na pastagem foram encontradas 10 famílias, 19 gêneros e 19 espécies de plantas; os componentes que apresentaram maior disponibilidade e participação foram o buffel e a orelha-de-onça, variando de 1.392 a 2.750; e 1.167 a $1.215 \mathrm{~kg}$ de massa seca (MS)/ha, com participação de 50 e $30 \%$ na composição da pastagem, respectivamente. A composição bromatológica da pastagem variou de 63,0 a 81,6; 3,3 a 5,2; 0,9 a 1,4; 69,3 a 76,0; 53,0 a 57,4; 5,2 a 8,9; 86,0 a 88,6; e 10,8 a 16,4\% para massa seca (MS), proteína bruta (PB), extrato etéreo (EE), fibras em detergente neutro (FDN) e ácido (FDA), material mineral (MM), carboidratos totais (CHOT) e não-fibrosos (CNF), respectivamente. A composição da extrusa variou de 18,5 a 22,3; 4,5 a 5,6; 1,3 a 1,9; 52,0 a 75,0; 52,3 a 59,8; 9,4 a 11,4; 81,8 a 84,4; 6,8 a 20,6; 45,7 a 49,1 para MS, PB,EE, FDN, FDA, MM, CHOT, CNF e digestibilidade in vitro da matéria seca (DIVMS), respectivamente.
\end{abstract}

Palavra-chave: BOTANAL, Cenchrus ciliares, extrusa

\section{Stockpiled Buffelgrass Pasture and Diet Selected Characterization during the Dry Season at the Semi Arid Region of Pernambuco State}

\begin{abstract}
The experiment aimed to determine the herbage mass and to evaluate the botanical and chemical composition of a stockpiled Buffelgrass pasture during the dry season. Visual estimates were accomplished for determination of the botanical composition. Samples were cut for forage availability determination. The data were processed by the BOTANAL program. Three esophagus fistulated animals were used to evaluate the quality and botanical composition of the selected diet. On the pasture a total of 10 families, 19 genus and 19 species of plants were observed. The botanical components that showed the highest herbage mass and participation were Buffel grass and "Orelha-de-onça" (Macroptilium martii Benth.), ranging from 1392 to $2750 \mathrm{~kg} \mathrm{DM} / \mathrm{ha}$ and $50 \%$ and, 1167 to $1215 \mathrm{~kg} \mathrm{DM} / \mathrm{ha}$ and 30\%, respectively. The forage chemical composition ranged from 63.0 to $81.6 \%, 3.3$ to $5.2 \%, 0.9$ to $1.4 \%, 69.3$ to $76.0 \%, 53.0$ to $57.4 \%, 5.2$ to $8.9 \%, 86.0$ to $88.6 \%$ and, 10.8 to $16.4 \%$ for dry matter (DM), crude protein (CP), ether extract (EE), neutral detergent fiber (NDF), acid detergent fiber (ADF), ashes (ASH), total carbohydrates $(\mathrm{TCH})$ and, no fiber carbohydrates (NFC), respectively. Extrusa chemical composition showed values ranging from 18.5 to $22.3 \%, 4.5$ to $5.6 \%, 1.3$ to $1.9 \%, 52.0$ to $75.0 \%, 52.3$ to $59.8 \%, 9.4$ to $11.4 \%, 81.8$ to $84.4 \%, 6.8$ to $20.6 \%$ and, 45.7 to $49.1 \%$ for DM, CP, EE, NDF, ADF, ASH, TCH, NFC and, "in vitro" dry matter digestibility, respectively.
\end{abstract}

Key Words: BOTANAL, Buffel grass, extrusa

\section{Introdução}

A vegetação nativa da caatinga do Nordeste caracteriza-se pela predominância de estrato arbustivo-arbóreo composto por plantas de baixo potencial forrageiro, que constituem o suporte ali- mentar básico da maioria das propriedades destinadas à pecuária nessa região. Além disso, apresenta baixa capacidade de suporte, resultando em baixo rendimento animal (Lima, 1984). Guimarães Filho et al. (1995) registraram valores de 0,08 UA/ha/ano, para a capacidade de suporte da caatinga, e produção

\footnotetext{
${ }_{1}$ Parte da Dissertação apresentada ao Programa de Pós-Graduação em Zootecnia-UFRPE e Trabalho realizado pelo Acordo IPA-UFRPE.

${ }^{2}$ Aluno do Programa de Doutorado Integrado em Zootecnia (gladstonrafael@yahoo.com.br).

3 Professora da UFRPE (aguim@ufrpe.br).

${ }^{4}$ Professor(a) da UFRPE. Bolsista CNPq (mercia@ufrpe.br, ferreira@ufrpe.br, mlira@ipa.br, dubeux@ufrpe.br).

${ }^{5}$ Zootecnista da UFRPE.
} 
de 6-8 kg de ganho de peso/ha/ano. Considerando-se apenas a estação chuvosa do ano, a capacidade de suporte da caatinga ficou em torno de 0,22 UA/ha.

Estudos desenvolvidos no Nordeste brasileiro evidenciam que $70 \%$ das espécies botânicas da caatinga participam significativamente da composição da dieta dos ruminantes domésticos. Gramíneas e leguminosas perfazem acima de $80 \%$ da dieta durante o período chuvoso. No período seco, com a queda das folhas da vegetação de porte mais alto, as espécies arbustivas e arbóreas ganham maior importância, particularmente na dieta de caprinos. A produção média anual de fitomassa da vegetação nativa da caatinga situase em torno de $4 \mathrm{t}$ de $\mathrm{MS} / \mathrm{ha}$, com substanciais variações advindas de diferenças nos sítios ecológicos e flutuações climáticas (Araújo Filho et al., 1995). Entretanto, desse total de fitomassa produzida, apenas cerca de $6 \%$ podem ser considerados como forragem quando a exploração é feita com bovinos, podendo chegar a $10 \%$ no caso de exploração com caprinos e ovinos (Mesquita et al., 1988).

A relação entre pastagens cultivadas e nativas é bastante ampla, chegando a atingir, em algumas regiões do sertão, valores em torno de 21,8 ha de pastagens nativas para 1,0 ha de pastagem cultivada (Moura,1987).

A aceitação do capim-buffel pelos pecuaristas, como a planta forrageira mais adaptada às condições semi-áridas do Nordeste, motivou diversas avaliações cujos resultados abrangeram vários aspectos do seu cultivo, manejo e utilização (Oliveira, 1993). A Austrália é um dos países que mais atenção têm dedicado ao cultivo de capim-buffel. Em 1981, este país possuía cerca de dois milhões de hectares plantados no estado de Queensland, dos quais 60\% em estado puro e $40 \%$ consorciado com outras gramíneas e/ou leguminosas (Paull \& Lee, citados por Ayerza, 1981).

O sistema CBL (caatinga-buffel-leucena) preconizado pelo Centro de Pesquisa Agropecuária do Trópico Semi-Árido (CPATSA) é muito próximo do sistema proposto por Moura (1987) e tem como principal diferença a utilização da leucena e de outras plantas forrageiras introduzidas ou nativas, que, durante o período chuvoso, devem ser cultivadas para produção de feno ou silagem, de modo que a rebrota de algumas espécies possa ser consumida a partir do início do período seco. A finalidade da Leucena e das outras espécies forrageiras é suprir a deficiência protéica do pasto de capim-buffel, que na época seca chega a teores de 3 a $4 \%$ de proteína bruta (Guimarães Filho et al., 1995).
A prática de diferimento leva a planta a avançar em seu estádio fenológico, influenciando positivamente o acúmulo de massa seca e negativamente a composição química e digestibilidade (Reis et al., 1997). Uma vez que a qualidade e a disponibilidade de forragem está diretamente relacionada ao consumo e, conseqüentemente, ao desempenho animal, torna-se evidente a necessidade de se considerar estes dois aspectos quando se pensa em diferimento de pastagens.

Segundo Maraschin (1986), o diferimento é uma prática excelente e, muitas vezes, evita a perda de animais. Porém, Neiva \& Santos (1998) chamam a atenção para o aspecto de que essa prática pode resultar em perdas da qualidade e quantidade da forragem reservada. Por outro lado, o diferimento de pastagem influencia a composição botânica da pastagem, conforme observado por Fernandes et al. (1983).

A determinação da dieta dos animais é de fundamental importância para os estudos da nutrição animal em pastagem, pois identificar as plantas ou parte das plantas mais preferidas e consumidas pelos animais, além de detectar as carências alimentares dos mesmos ao longo do ano (Peter, 1992).

Neste trabalho, objetivou-se caracterizar um pasto de capim-buffel diferido e avaliar a composição botânica e bromatológica da pastagem e da dieta de bovinos, durante o período seco no sertão pernambucano.

\section{Material e Métodos}

O experimento foi realizado na Estação Experimental de Serra Talhada, da Empresa Pernambucana de Pesquisa Agropecuária - IPA, durante o período de setembro a dezembro de 2001, quando foram registradas precipitação média mensal de $35,04 \mathrm{~mm}$ e temperatura média mensal de $24,2^{\circ} \mathrm{C}$, com média de máxima e mínima de $32,9^{\circ} \mathrm{e} 21,4^{\circ} \mathrm{C}$, respectivamente. Na classificação de Thornthwaite, o clima da região é o tipo DdA'a' Semi-Árido, característico da área do polígono das secas com duas estações bem definidas (Encarnação, 1980).

O solo predominante na área experimental é do tipo Bruno Não Cálcico, considerado típico e representativo da região, apresentando também manchas de Podzólico Vermelho Amarelo Eutrófico, textura arenosa média e relevo suave ondulado (IPA, 1986). A cobertura florística da região é do tipo caatinga, bastante complexa e irregular com predominância de arbustos e árvores e um estrato herbáceo bastante escasso (Moura,1987).

\section{R. Bras. Zootec., v.34, n.2, p.454-463, 2005}


A área de pastagem foi fechada no início do período chuvoso anterior (dezembro de 1999), não recebeu adubação, e passou ser utilizada somente no início de setembro de 2000.

A área total da pastagem foi de 7,5 ha, destinados a oito vacas e três novilhos fistulados no esôfago. No final de cada período experimental de 21 dias, os animais (vacas e novilhos fistulados) foram retirados da área para que fosse realizada a avaliação da disponibilidade e composição botânica da pastagem.

A estimativa da disponibilidade de forragem total foi obtida pelo método do rendimento comparativo (Haydock \& Shaw ,1975), enquanto os dados para estimar a composição botânica foram obtidos pelo método do peso seco ordenado, descrito por Manetje \& Haydock (1963), modificado por Jones \& Hargreaves (1979). Para o processamento dos dados, foi empregado o programa computacional BOTANAL (Hargreaves \& Kerr, 1978).

O índice de seletividade (Hodgson, 1979) foi obtido pelo quociente entre a porcentagem da espécie na dieta e na pastagem.

$\mathrm{Na}$ área, foram traçados 10 transectos paralelos, distanciados entre si a, aproximadamente, 20 metros, e em cada um, foram realizadas 12 estimativas visuais, totalizando 120 pontos observados.

Utilizou-se um quadrado de ferro medindo $0,50 \mathrm{x}$ $0,50 \mathrm{~cm}$ para a estimativa da composição botânica e disponibilidade de forragem. As quinze amostras referentes aos padrões foram pesadas e secas em estufa a $55^{\circ} \mathrm{C}$, por 48 horas, para posterior análise da composição bromatológica do pasto de acordo com Silva \& Queiroz (2002).

Para avaliar a dieta, a cada período de avaliação, durante sete dias consecutivos, foram realizadas coletas com três animais fistulados no esôfago, que eram contidos em um curral no final da tarde e submetidos a jejum por, aproximadamente, 16 horas. $\mathrm{Na}$ manhã seguinte, eram retiradas as cânulas e colocadas bolsas coletoras confeccionadas em lona impermeável, contendo tela de náilon no fundo. $\mathrm{O}$ período de pastejo era de cerca de 20 minutos, suficiente para que as bolsas coletoras ficassem cheias. Em seguida, as bolsas eram retiradas, as amostras recolhidas, espremidas para a retirada do excesso de saliva, e, em seguida, acondicionadas em sacos plásticos devidamente identificados e armazenadas em freezer.

Para a análise da extrusa coletada, após descongelamento, a amostra foi dividida em duas porções, uma utilizada para determinação da composição bromatológica, realizando-se as análises de matéria seca (MS), proteína bruta (PB), extrato etéreo (EE), fibra em detergente neutro (FDN), fibra em detergente ácido (FDA) e matéria mineral (MM), conforme Silva \& Queiroz (2002). A estimativa dos teores de carboidratos totais (CHOT) foram de acordo com a fórmula: $\mathrm{CHOT}=100-(\mathrm{PB}+\mathrm{EE}+\mathrm{MM})$, descrita por Sniffen et al., (1992), e a dos carboidratos nãofibrosos (CNF), pela fórmula: $\mathrm{CNF}=100-(\mathrm{FDN}+\mathrm{PB}$ $+\mathrm{EE}+\mathrm{MM})$, conforme Mertens (1997). A outra porção da extrusa foi utilizada para determinar a composição botânica da dieta, pela técnica do ponto microscópico descrita por Heady \& Torrel (1959).

Uma amostra da extrusa foi enviada ao Laboratório de Nutrição Animal da Embrapa Semi-Árido, Petrolina - PE, para determinação da digestibilidade in vitro da matéria seca.

Os dados foram analisados a partir da comparação de médias pelo teste Tukey a $5 \%$ de probabilidade, por intermédio do procedimento estatístico SAS (1997).

\section{Resultados e Discussão}

Foram encontradas 10 famílias, 19 gêneros e 19 espécies de plantas na pastagem avaliada (Tabela 1). As espécies identificadas são típicas da vegetação de caatinga, como observado também por Moura (1987) e Silva (1988).

A massa total de forragem variou de 4.968 a $3.169 \mathrm{~kg}$ de MS/ha nos meses de setembro a dezembro (Tabela 2), que correspondem ao período seco da região.

Foi observada redução significativa ao longo dos meses para a massa de forragem disponível de capim-buffel, que passou de $2.750 \mathrm{~kg} / \mathrm{MS} / \mathrm{ha}$ em setembro para $1392 \mathrm{~kg} / \mathrm{MS} / \mathrm{ha}$ em dezembro. Entretanto, a amplitude observada na disponibilidade do componente em cada mês é muito pequena. Ao analisarmos o componente ervas e arbustos, observamos comportamento semelhante, possivelmente devido ao seu consumo pelos animais, visto que eram um dos poucos componentes da pastagem que se manteve verde durante quase todo o período experimental.

Vale ressaltar que, segundo Minson (1981), a quantidade mínima de forragem para garantir a máxima ingestão pelos animais é de $1.000 \mathrm{~kg}$ MS/ha. Deve-se salientar que, em pastagens de pior valor nutritivo, é necessário maior disponibilidade de forragem para garantir adequada seleção pelos animais. Porém, Gomide (1998) orienta que, em sistemas que 
Tabela 1 - Espécies encontradas nos piquetes experimentais

Table 1 - Species found in the experimental area

\begin{tabular}{|c|c|c|}
\hline $\begin{array}{l}\text { Nome vulgar } \\
\text { Common name }\end{array}$ & $\begin{array}{l}\text { Nome científico } \\
\text { Scientific name }\end{array}$ & $\begin{array}{l}\text { Família } \\
\text { Family }\end{array}$ \\
\hline Alento & Gonfrena vaga Mart. & Amaranthaceae \\
\hline Algodão de seda & Calotropis procera (Ait.)R. Br. & Asclepiadeceae \\
\hline Aroeira & Astronium urundeuva Engl. & Anacardiacea \\
\hline Baraúna & Schinopsis brasiliensis Engl. & Anacardiacea \\
\hline Canafístula & Caessia escelea Scharad. & Leguminosae \\
\hline Capa bode & Melochia tomentosa $\mathrm{L}$. & Sterculiaceae \\
\hline Capim-buffel & Cenchrus ciliaris L. & Gramineae \\
\hline Catingueira & Caesalpinea ferrea Mart. & Leguminosae \\
\hline Ervanso & Alternanthera tenella colla. & Amaranthaceae \\
\hline Feijãozinho & Centrosema sp. & Leguminosae \\
\hline Jitirana & Ipomoea sp. & Convolvulaceae \\
\hline Juazeiro & Ziziphus joazeiro & Rhamnaceae \\
\hline Jurema preta & Mimosa nigra. & Leguminosae \\
\hline Malícia & Mimosa sp. & Leguminosae \\
\hline Malva-preta & Malvastrum sp. & Malvaceae \\
\hline Mato de embrejado & Diodia teres Walt. & Rubiaceae \\
\hline Melosa & Herissantia tiubae (K. schum.) Briz & Malvaceae \\
\hline Moleque-duro & Cordia leucocephala Moric. & Ehretiacea \\
\hline Mororó & Bauhinia cheillantha Steud. & Leguminosae \\
\hline Orelha-de-onça & Macroptilium martii Benth. & Leguminosae \\
\hline
\end{tabular}

Tabela 2 - Massa de forragem (kg MS/ha) nos meses correspondente a época seca Table 2 - Herbage mass ( $\mathrm{kg} \mathrm{DM} / \mathrm{ha}$ ) during the dry season

\begin{tabular}{|c|c|c|c|c|}
\hline \multirow[t]{2}{*}{$\begin{array}{l}\text { Espécie } \\
\text { Specie }\end{array}$} & \multicolumn{4}{|c|}{$\begin{array}{c}\text { Mês de avaliação } \\
\text { Evaluation month }\end{array}$} \\
\hline & $\begin{array}{l}\text { Setembro } \\
\text { September }\end{array}$ & $\begin{array}{l}\text { Outubro } \\
\text { October }\end{array}$ & $\begin{array}{l}\text { Novembro } \\
\text { November }\end{array}$ & $\begin{array}{l}\text { Dezembro } \\
\text { December }\end{array}$ \\
\hline Capim-buffel & $2750 \pm 90 \mathrm{a}$ & $2298 \pm 44 b$ & $1845 \pm 2 c$ & $1392 \pm 48 d$ \\
\hline Orelha-de-onça & $1167 \pm 131 \mathrm{a}$ & $1183 \pm 159 a$ & $1199 \pm 186 a$ & $1215 \pm 213 a$ \\
\hline Malva-preta & $222 \pm 89 a$ & $264 \pm 109 a$ & $307 \pm 129 a$ & $350 \pm 149 \mathrm{a}$ \\
\hline Ervas e arbustos & $829 \pm 71 a$ & $623 \pm 28 b$ & $418 \pm 14 c$ & $212 \pm 57 d$ \\
\hline Total & $4968 \pm 37 a$ & $4368 \pm 14 \mathrm{ab}$ & $3769 \pm 385 b c$ & $3169 \pm 356 c$ \\
\hline
\end{tabular}

Médias seguidas pela mesma letra, nas linhas, não diferem entre si a $5 \%$ de probabilidade pelo teste Tukey. Means within a row, followed by same letter, did not differ $(P<.05)$ by Tukey test.

utilizam lotação contínua para maximizar a produção de leite por vacas, a disponibilidade de massa seca verde/ha deve estar em torno de 1.500 a $2.500 \mathrm{~kg}$. Ramirez et al. (1995) comentam que a disponibilidade de forragem em pastagens no semi-árido varia muito em função do clima, propiciando uma nutrição de qualidade variável para os animais. Este último comenta ainda que, em outros locais, no México, por exemplo, as pastagens de capim-buffel têm sua composição e qualidade bastante alteradas durante o inverno, se comparadas àquela observada durante o verão.

É importante, ao se analisar a massa de forragem, verificar se os valores obtidos são somente do mate- rial verde disponível ou se foi considerada também a fração de material morto. Na ocorrência da segunda situação, é provável que a disponibilidade esteja sendo superestimada, principalmente em áreas onde o diferimento foi aplicado, uma vez que, com esta prática, a disponibilidade de forragem é elevada, ao passo que a qualidade da forragem torna-se questionável.

Este fato foi observado no experimento, principalmente em relação à leguminosa orelha-de-onça, pois, embora o diferimento tenha permitido bom desenvolvimento da forragem, boa parte desse material correspondia à fração de material morto, que é 
pouco aproveitada pelo animal, justificando seu baixo consumo pelos animais e sua permanência na pastagem, fazendo com que sua disponibilidade em relação ao total de massa forrageira e sua participação na composição botânica tenha aumentado no decorrer dos meses. Desta forma, sugere-se que, em experimentos posteriores, realizados em pastos diferidos, seja avaliada, além da massa seca verde disponível na pastagem, também a fração de material morto, para que se possa determinar com melhor precisão a disponibilidade de forragem.

Observa-se que, em todos os períodos experimentais, a disponibilidade total de forragem apresentou-se acima dos valores considerados limitantes por Minson (1981) e Reis et al. (1997). Os valores da disponibilidade total de forragem foram superiores aos relatados por Fernandes et al. (1983) e Moura (1987), porém inferiores aos obtidos por Silva et al.(1987), ao trabalharem no sertão de Pernambucano. Porém, deve-se considerar as diferenças referentes aos períodos de diferimento e as espécies envolvidas.

Souza \& Espíndola (1999), trabalhando com ovinos, estudaram a disponibilidade do pasto de capimbuffel durante o período seco e encontraram produção semelhante à deste trabalho, com disponibilidade inicial de $6.862 \mathrm{~kg} \mathrm{MS} / \mathrm{ha}$ no inicio da estação seca, chegando a atingir $2185 \mathrm{~kg} \mathrm{MS} / \mathrm{ha}$ no final da estação. Assis (1992), em experimentos realizado na estação do IPA, em Serra Talhada, avaliou diferentes épocas de abertura do pasto de capim-buffel diferido sobre o ressurgimento da leguminosa orelha-de-onça e observou que a vedação dos pastos de capim-buffel durante todo o período chuvoso, com abertura no início do período seco, foi o manejo mais recomendado para os pastos cultivados nas condições de semiárido, para proporcionar condições de a leguminosa florescer, frutificar, produzir sementes viáveis e perpetuar-se, contribuindo para o aumento de sua participação na disponibilidade de matéria seca e produção de forragem de melhor valor nutritivo ao longo dos anos.

A área experimental era formada predominantemente, pelo capim-buffel, independente do mês avaliado (Tabela 3). Entretanto, o consumo desta forragem pelos animais fez com que sua porcentagem de participação fosse reduzida com o passar dos meses. A leguminosa orelha-de-onça teve participação expressiva (em torno de 30\%), o que indica que, ao longo dos anos, houve persistência na participação da leguminosa, podendo-se considerar a existência de duas espécies "índex" nesta pastagem. Deve-se considerar ainda que o comportamento observado para o componente malva preta e ervas e arbustos foi igual em relação à disponibilidade destas forragens. Portanto, há grande resistência do capim-buffel às condições edafoclimáticas do semi-árido, tendo em vista sua persistência na pastagem quando se adota uma pressão de pastejo adequada.

O comportamento da composição botânica verificado em pastagens de capim-buffel foi semelhante ao reportado por Souza \& Espíndola (1999), que obtiveram valores de 76 e $24 \%$ para o capim-buffel e outras espécies, respectivamente.

Os percentuais de participação da leguminosa orelha-de-onça encontrados neste experimento foram muito próximos daqueles relatados por Silva \& Faria (1989), que, em trabalho realizado em Serra Talhada - PE, estudaram durante quatro anos o comportamento da leguminosa orelha-de-onça e obtiveram participação de cerca de $33 \%$ desta espécie.

Os índices de seletividade observados (Tabela 4) indicam que o capim-buffel foi selecionado durante

Tabela 3 - Composição botânica da pastagem (\%) nos meses correspondentes a época seca Table 3 - Pasture botanical composition (\%) during the dry season

\begin{tabular}{|c|c|c|c|c|}
\hline \multirow[t]{2}{*}{$\begin{array}{l}\text { Espécie } \\
\text { Specie }\end{array}$} & \multicolumn{4}{|c|}{$\begin{array}{l}\text { Mês de avaliação } \\
\text { Evaluation month }\end{array}$} \\
\hline & $\begin{array}{l}\text { Setembro } \\
\text { September }\end{array}$ & $\begin{array}{l}\text { Outubro } \\
\text { October }\end{array}$ & $\begin{array}{l}\text { Novembro } \\
\text { November }\end{array}$ & $\begin{array}{l}\text { Dezembro } \\
\text { December }\end{array}$ \\
\hline $\begin{array}{l}\text { Capim-buffel } \\
\text { Orelha-de-onça } \\
\text { Malva-preta } \\
\text { Ervas e arbustos }\end{array}$ & $\begin{array}{l}55,35 \mathrm{a} \\
23,49 \mathrm{a} \\
4,47 \mathrm{a} \\
16,68 \mathrm{a}\end{array}$ & $\begin{array}{l}52,60 \mathrm{ab} \\
27,08 \mathrm{ab} \\
6,04 \mathrm{ab} \\
14,26 \mathrm{ab}\end{array}$ & $\begin{array}{l}48,95 \mathrm{bc} \\
31,81 \mathrm{bc} \\
8,14 \mathrm{ab} \\
11,09 \mathrm{bc}\end{array}$ & $\begin{array}{l}43,92 \mathrm{c} \\
38,34 \mathrm{c} \\
11,04 \mathrm{~b} \\
6,68 \mathrm{c}\end{array}$ \\
\hline
\end{tabular}

Médias seguidas pela mesma letra, nas linhas, não diferem entre si a $5 \%$ de probabilidade pelo teste Tukey.

Means within a row, followed by same letter, did not differ $(P<.05)$ by Tukey test.

R. Bras. Zootec., v.34, n.2, p.454-463, 2005 
todos os meses de avaliação, sendo o maior valor obtido no mês de dezembro, possivelmente em decorrência da tentativa do animal em buscar uma forragem de melhor qualidade, visto que este mês coincide com o final do período seco, quando há menor disponibilidade da forragem. O índice de seletividade do componente ervas e arbustos foi baixo, não diferindo em relação aos meses avaliados, em virtude da redução na sua disponibilidade e participação na composição botânica da pastagem.

No final do período experimental (novembro/dezembro), o índice de seleção do componente malva-preta foi maior que no início (setembro/outubro), em decorrência do aumento de sua disponibilidade em relação à massa total disponível e da maior porcentagem na composição botânica da pastagem, em relação aos outros componentes. Houve algumas variações no comportamento seletivo do animal, provavelmente pelo fato de algumas forrageiras apresentarem-se em estádios de desenvolvimento distintos, conforme os meses de avaliação.
Ao se avaliar a composição bromatológica do capim-buffel (Tabela 5), deve-se considerar que o pasto, ao ser diferido no final das chuvas, não foi adubado, o que pode ter influenciado a composição bromatológica das forrageiras ao longo do experimento.

Os teores de MS (Tabela 6) na pastagem elevaram ao longo dos meses em razão da redução na percentagem de folha e do aumento na percentagem de caule na pastagem (Tabelas 7 e 8 ).

Fernandes et al. (1983), trabalhando com capimde-raiz (Chloris orthonoton, Doell) diferido por um período de 90 dias, obtiveram teores de matéria seca em torno de 51,30\%, enquanto Moura (1987), trabalhando com capim-buffel sob diferimento na região de Serra Talhada - PE, obteve teores de 90\% de matéria seca, o que grande variação no teor de matéria seca e dos demais componentes do pasto diferido, em relação à espécie escolhida e ao tempo de diferimento.

Tabela 4 - Índice de seletividade dos animais em pasto diferido

Table 4 - Seletivity index of animals in stockpiled Buffelgrass pasture

\begin{tabular}{|c|c|c|c|c|}
\hline \multirow[t]{2}{*}{$\begin{array}{l}\text { Espécie } \\
\text { Specie }\end{array}$} & \multicolumn{4}{|c|}{$\begin{array}{l}\text { Mês de avaliação } \\
\text { Evaluation month }\end{array}$} \\
\hline & $\begin{array}{l}\text { Setembro } \\
\text { September }\end{array}$ & $\begin{array}{c}\text { Outubro } \\
\text { October }\end{array}$ & $\begin{array}{c}\text { Novembro } \\
\text { November }\end{array}$ & $\begin{array}{l}\text { Dezembro } \\
\text { December }\end{array}$ \\
\hline Capim-buffel & $1,49 \mathrm{a}$ & $1,40 \mathrm{a}$ & $1,46 \mathrm{a}$ & $1,80 \mathrm{~b}$ \\
\hline Orelha-de-onça & $0,44 \mathrm{ab}$ & $0,69 \mathrm{a}$ & $0,51 \mathrm{a}$ & $0,18 b$ \\
\hline Malva-preta & $0,15 \mathrm{a}$ & $0,18 \mathrm{a}$ & $0,83 b$ & $1,06 b$ \\
\hline Ervas e arbustos & $0,31 \mathrm{a}$ & $0,32 \mathrm{a}$ & $0,17 \mathrm{a}$ & 0,00 \\
\hline
\end{tabular}

Médias seguidas pela mesma letra, nas linhas, não diferem entre si a $5 \%$ de probabilidade pelo teste Tukey.

Means within a row, followed by same letter, did not differ $(P<.05)$ by Tukey test.

Tabela 5 - Teores médios de matéria seca (MS), proteína bruta (PB), extrato etéreo (EE), fibra em detergente neutro (FDN), fibra em detergente ácido (FDA), matéria mineral (MM), carboidratos totais (CHOT) e não-fibrosos (CNF), dos componentes da pastagem de capim-buffel diferido ao longo dos meses do período seco

Table 5 - Average concentrations of dry matter (DM), crude protein (CP), ether extract (EE), neutral detergent fiber (NDF), acid detergent fiber (ADF), ashes (ASH), total carbohydrates (TCH) and nonfiber carbohydrates (NFC) of Buffelgrass stockpiled pasture components, during the dry season

\begin{tabular}{|c|c|c|c|c|c|c|c|c|}
\hline \multirow[t]{3}{*}{$\begin{array}{l}\text { Mês } \\
\text { Month }\end{array}$} & \multicolumn{8}{|c|}{$\begin{array}{l}\text { Nutriente (\% na MS) } \\
\text { Nutrient (\% in DM basis) }\end{array}$} \\
\hline & MS & PB & $\mathrm{EE}$ & FDN & FDA & MM & CHOT & $\mathrm{CNF}$ \\
\hline & $D M$ & $C P$ & $E E$ & $N D F$ & $A D F$ & $A S H$ & $\mathrm{TCH}$ & $N F C$ \\
\hline Setembro (September) & $63,00 \mathrm{~b}$ & $5,23 \mathrm{a}$ & $1,08 \mathrm{a}$ & $74,23 \mathrm{ab}$ & $57,47 a$ & $5,14 \mathrm{c}$ & $88,55 \mathrm{a}$ & $14,32 \mathrm{ab}$ \\
\hline Outubro (October) & $77,00 \mathrm{a}$ & $3,73 b$ & $1,40 \mathrm{a}$ & $69,31 b$ & $53,02 \mathrm{c}$ & $8,91 \mathrm{a}$ & $85,96 b$ & $16,38 \mathrm{a}$ \\
\hline Novembro (November) & $80,00 \mathrm{a}$ & $4,97 \mathrm{c}$ & $0,94 \mathrm{a}$ & $76,02 \mathrm{a}$ & $54,64 b c$ & $7,27 \mathrm{~b}$ & $86,82 \mathrm{ab}$ & $10,80 b$ \\
\hline Dezembro(December) & $81,60 \mathrm{a}$ & $3,37 d$ & $1,40 \mathrm{a}$ & $73,41 \mathrm{ab}$ & $55,91 \mathrm{ab}$ & $7,11 \mathrm{~b}$ & $88,12 \mathrm{a}$ & $14,71 \mathrm{ab}$ \\
\hline
\end{tabular}

Médias seguidas pela mesma letra, nas colunas, não diferem entre si a $5 \%$ de probabilidade pelo teste Tukey.

Means within a row, followed by same letter, did not differ $(P<.05)$ by Tukey test.

R. Bras. Zootec., v.34, n.2, p.454-463, 2005 
Tabela 6 - Teores de matéria seca (MS), proteína bruta (PB), extrato etéreo (EE), fibra em detergente neutro (FDN), fibra em detergente ácido (FDA), matéria mineral (MM), carboidratos totais (CHOT) e não-fibrosos (CNF) e digestibilidade in vitro da matéria seca (DIVMS) da extrusa de animais pastejando durante o período seco em pasto de capim-buffel diferido

Table 6 - Average concentrations of dry matter (DM), crude protein (CP), ether extract (EE), neutral detergent fiber (NDF), acid detergent fiber (ADF), ashes (ASH), total carbohydrates (TCH), nonfiber carbohydrates (NFC) and in vitro dry matter digestibility (IVDMD) from the diet of esophageal fistulated animals grazing on Buffelgrass stockpiled pasture, during the dry season

\begin{tabular}{lccccccccc}
\hline $\begin{array}{l}\text { Mês } \\
\text { Month }\end{array}$ & \multicolumn{8}{c}{$\begin{array}{c}\text { Nutriente (\% na MS) } \\
\text { Nutrient (\% in DM basis) }\end{array}$} \\
\cline { 2 - 11 } & MS & PB & EE & FDN & FDA & MM & CHOT & CNF & DIVMS \\
& $D M$ & $C P$ & $E E$ & $N D F$ & $A D F$ & $A S H$ & $T C H$ & $N F C$ & $I V D D M$ \\
\hline Setembro (September) & $20,33 \mathrm{a}$ & $5,63 \mathrm{a}$ & $1,97 \mathrm{a}$ & $75,00 \mathrm{a}$ & $52,32 \mathrm{~b}$ & $10,52 \mathrm{a}$ & $81,88 \mathrm{a}$ & $6,80 \mathrm{~b}$ & $49,15 \mathrm{a}$ \\
Outubro (October) & $22,32 \mathrm{a}$ & $4,87 \mathrm{c}$ & $1,33 \mathrm{a}$ & $69,00 \mathrm{ab}$ & $54,58 \mathrm{ab}$ & $9,37 \mathrm{a}$ & $84,43 \mathrm{a}$ & $15,43 \mathrm{ab}$ & $45,75 \mathrm{a}$ \\
Novembro (November) & $21,24 \mathrm{a}$ & $5,22 \mathrm{~b}$ & $1,74 \mathrm{a}$ & $66,00 \mathrm{ab}$ & $59,83 \mathrm{a}$ & $10,43 \mathrm{a}$ & $82,61 \mathrm{a}$ & $16,68 \mathrm{ab}$ & $47,97 \mathrm{a}$ \\
Dezembro(December) & $18,51 \mathrm{a}$ & $4,48 \mathrm{~d}$ & $1,50 \mathrm{a}$ & $62,00 \mathrm{~b}$ & $58,94 \mathrm{a}$ & $11,44 \mathrm{a}$ & $82,58 \mathrm{a}$ & $20,58 \mathrm{a}$ & $48,00 \mathrm{a}$ \\
\hline
\end{tabular}

Médias seguidas pela mesma letra, nas colunas, não diferem entre si a $5 \%$ de probabilidade pelo teste Tukey.

Means within a row, followed by same letter, did not differ $(P<.05)$ by Tukey test.

Tabela 7 - Percentual de folha das espécies presente na extrusa de animais mantidos em pasto de capim-buffel diferido durante o período seco

Table 7 - Percentage of leaves from species present in the diet of esophageal fistulated animals grazing on stockpiled Buffelgrass pasture during the dry season

\begin{tabular}{|c|c|c|c|c|}
\hline \multirow[t]{2}{*}{$\begin{array}{l}\text { Espécie } \\
\text { Specie }\end{array}$} & \multicolumn{4}{|c|}{$\begin{array}{l}\text { Mês de avaliação } \\
\text { Evaluation month }\end{array}$} \\
\hline & $\begin{array}{l}\text { Setembro } \\
\text { September }\end{array}$ & $\begin{array}{c}\text { Outubro } \\
\text { October }\end{array}$ & $\begin{array}{c}\text { Novembro } \\
\text { November }\end{array}$ & $\begin{array}{l}\text { Dezembro } \\
\text { December }\end{array}$ \\
\hline Capim-buffel & $59,92 \mathrm{a}$ & $41,33 b$ & $29,43 c$ & $29,92 c$ \\
\hline Orelha-de-onça & $8,17 a b$ & $12,08 \mathrm{a}$ & $6,50 \mathrm{bc}$ & $2,50 \mathrm{c}$ \\
\hline Malva-preta & $2,0 \mathrm{~b}$ & $2,25 b$ & $5,08 \mathrm{a}$ & $8,00 \mathrm{a}$ \\
\hline Jurema & $1,33 \mathrm{a}$ & $2,38 \mathrm{a}$ & 0 & 0 \\
\hline Juazeiro & $1,88 \mathrm{a}$ & $2,38 \mathrm{a}$ & 0 & 0 \\
\hline Algodão de seda & $2,42 \mathrm{a}$ & $1,50 \mathrm{a}$ & 0 & 0 \\
\hline
\end{tabular}

Médias seguidas pela mesma letra, nas linhas, não diferem entre si a $5 \%$ de probabilidade pelo teste Tukey.

Means within a row, followed by same letter, in the lines, did not differ $(P<.05)$ by Tukey test.

Tabela 8 - Percentual de caule das espécies presente na extrusa de animais mantidos em pasto de capim-buffel diferido durante o período seco

Table 8 - Percentage of stems from species present in the diet of esophageal fistulated animals grazing on stockpiled Buffelgrass pasture during the dry season

\begin{tabular}{|c|c|c|c|c|}
\hline \multirow[t]{2}{*}{$\begin{array}{l}\text { Espécie } \\
\text { Specie }\end{array}$} & \multicolumn{4}{|c|}{$\begin{array}{c}\text { Mês de avaliação } \\
\text { Evaluation month }\end{array}$} \\
\hline & $\begin{array}{l}\text { Setembro } \\
\text { September }\end{array}$ & $\begin{array}{c}\text { Outubro } \\
\text { October }\end{array}$ & $\begin{array}{c}\text { Novembro } \\
\text { November }\end{array}$ & $\begin{array}{l}\text { Dezembro } \\
\text { December }\end{array}$ \\
\hline Capim-buffel & $22,33 d$ & $32,33 c$ & $41,83 b$ & $52,00 \mathrm{a}$ \\
\hline Orelha-de-onça & $2,25 \mathrm{~d}$ & $6,67 b$ & $9,75 \mathrm{a}$ & $4,42 \mathrm{c}$ \\
\hline Malva-preta & 0 & $1,00 \mathrm{c}$ & $1,67 \mathrm{~b}$ & $3,5 \mathrm{a}$ \\
\hline Jurema & 0 & $1,00 \mathrm{a}$ & $1,00 \mathrm{a}$ & 0 \\
\hline Juazeiro & 0 & 0 & 0 & 0 \\
\hline Algodão de seda & 0 & 0 & 0 & 0 \\
\hline
\end{tabular}

Médias seguidas pela mesma letra, nas linhas, não diferem entre si a $5 \%$ de probabilidade pelo teste Tukey.

Means within a row, followed by same letter, in the lines, did not differ $(P<.05)$ by Tukey test.

R. Bras. Zootec., v.34, n.2, p.454-463, 2005 
O teor de proteína bruta do pasto diferido foi de $5,23 \%$ no início do experimento, com comportamento linear decrescente, chegando a 3,37\% no último mês de avaliação. Estes valores foram semelhantes aos relatados por Fonseca \& Escuder (1983) e Souza \& Espíndola (1999), que podem ser considerados baixos do ponto de vista nutricional, posto que os bovinos precisam de, no mínimo, 7,0\% de proteína para que possam alcançar níveis de consumo e digestibilidade suficientes para sua manutenção.

As diferenças observadas no teor de proteína bruta na extrusa coletada pode ser atribuída à seletividade dos animais, que proporcionou uma dieta de composição melhor que a obtida no pasto, para este nutriente. Para os teores de FDN e FDA, as diferenças entre o pasto e a extrusa foram menos evidentes, pois, com o deferimento, ocorre o avanço da idade da planta e aumento da fração menos digestível e do material morto no pasto, limitando a seletividade dos animais por partes menos fibrosas.

A digestibilidade in vitro da matéria seca (DIVMS) da extrusa não diferiu ao longo dos meses (Tabela 6), mas seu valor foi baixo quando comparado com os citados por Lira et al. (1987), que variaram de 58,4 a 68,8\% dependendo da idade e da estação de crescimento do capim, o que reforça o fato de que, durante o período seco, com a ausência das chuvas que possibilitam a renovação das pastagens, o pasto remanescente perde rápido e progressivamente o seu valor nutricional (Mesquita, 1985).

Ramirez et al. (1995) avaliaram durante um ano o comportamento ingestivo de carneiros em pastagens de capim-buffel e observaram que, durante alguns meses do ano, os animais conseguiam obter, por meio da seleção, os nutrientes necessários para mantença e ganho de peso, em virtude da qualidade da pastagem, enquanto, em outros meses, em virtude da baixa qualidade da pastagem, a seleção efetuada pelo carneiros foi suficiente apenas para atender seus requerimentos de mantença.

Observa-se que, com o passar dos meses, a porcentagem de folhas na extrusa referente ao capim-buffel foi reduzida em 50\%, chegando, no mês de dezembro, a representar apenas $30 \%$ das folhas consumidas (Tabela 7). Comportamento semelhante foi apresentado pela leguminosa orelha-de-onça, que teve redução na sua participação na ordem de $70 \%$, representando apenas $2,5 \%$ das folhas consumidas em dezembro. Entretanto, a malva-preta, no decorrer do período, apresentou aumento expressivo de $400 \%$ na participação de suas folhas na dieta dos animais, o que pode ser justificado pela tentativa do animal em melhorar sua dieta, uma vez que houve redução na disponibilidade de folhas de gramíneas e leguminosas, levando-o a buscar partes mais tenras e, possivelmente, mais digestíveis no estrato herbáceo disponível.

Ressalta-se que, no início do experimento, foram identificadas participações na extrusa, mesmo que pequenas de outras espécies forrageiras, como o juazeiro, algodão de seda e jurema, plantas que ainda se encontravam verdes nestes meses. Entretanto, no decorrer do tempo, estas espécies desapareceram, em decorrência do seu consumo pelos animais, não sendo detectadas na extrusa nos últimos períodos avaliados.

Ao longo dos meses, observou-se redução na disponibilidade de folhas do capim-buffel e conseqüente aumento na fração caule (Tabela 8). Para o capim-buffel, esse avanço chegou a $132 \%$, apresentando comportamento linear crescente. O mesmo comportamento foi apresentado pela leguminosa orelha-de-onça até o mês de novembro, sendo o aumento em torno de $192 \%$. Em dezembro, houve redução no percentual de caule e no de folha presentes na dieta, em virtude da baixa qualidade da leguminosa neste mês (final do período experimental), pois havia muito material pisoteado e quase toda a leguminosa encontrava-se morta.

Era esperada maior participação da leguminosa orelha-de-onça na dieta, em razão da tentativa dos bovinos de suprirem suas necessidades em proteína. No entanto, pelo fato do experimento ter iniciado em setembro, a leguminosa já havia ultrapassado seu período de florescimento e encontrava-se quase que totalmente em senescência, o que pode ter influenciado a baixa participação da leguminosa na dieta.

\section{Conclusões}

O uso do diferimento em pastos de capim-buffel pode garantir disponibilidade total de massa forrageira suficiente para atender o bom nível de consumo pelos animais durante o período seco.

A composição botânica da pastagem variou com o avanço do período seco e o pastejo dos animais.

Os níveis de nutrientes e de digestibilidade indicaram ser o pasto de capim-buffel diferido de qualidade pobre ou regular. 


\section{Literatura Citada}

ARAÚJO FILHO, J.A.; SOUSA, F.B.; CARVALHO, F.C. Pastagens no semi-árido: Pesquisa para o desenvolvimento sustentável. In: SIMPÓSIO SOBRE PASTAGENS NOS ECOSSISTEMAS BRASILEIROS - Pesquisas para o desenvolvimento sustentável, 1995, Brasília. Anais... Brasília: Sociedade Brasileira de Zootecnia, 1995. p.63-75.

ASSIS, W.P. Efeito da época de abertura da pastagem de capim buffel (Cenchurs ciliairis) no ressurgimento da leguminosa natural orelha-de-onça (Macropitilium martii Benth). Recife: Universidade Federal Rural de Pernambuco, 1992. 85p. Dissertação (Mestrado em Zootecnia) - Universidade Federal Rural de Pernambuco, 1992.

AYERZA, R. El buffel grass: utilidad y manejo de uma promissora graminea. Buenos Aires: Editoral Hermistério Sur, 1981. 139p.

ENCARNAÇÃO, C.R.F. Observações meteorológicas e tipos climáticos das unidades e campos experimentais da empresa IPA. Recife: Empresa Pernambucana de Pesquisa Agropecuária, 1980.110p.

FERNANDES, A.P.M.; FARIAS,I.; LIRA,M.A. et al. Efeito de diferentes períodos de deferimento sobre o pasto de capim de raiz (chloris orthonoton, Doell). In: CONGRESSO BRASILEIRO DE FORRAGEIRAS E PASTAGENS NATIVAS, Olinda, 1983. Anais... Olinda: Empresa Pernambucana de Pesquisa Agropecuária - IPA e Empresa Brasileira de Pesquisa Agropecuária - EMBRAPA, 1983.

FONSECA, D.M.; ESCUDER,C.J. Carga animal e produtividade em pastagens de capim buffel. Revista Brasileira de Zootecnia, v.12, n.1, p.11-24, 1983.

GOMIDE, J.A. Fatores da produção de leite a pasto. In: CONGRESSO NACIONAL DOS ESTUDANTES DE ZOOTECNIA, 1998, Viçosa, MG. Anais... Viçosa, MG: Universidade Federal de Viçosa, 1998. p.1-32.

GUIMARÃES FILHO, C.; SOARES, J.G.G.; RICHÉ, G.R. Sistema caatinga-buffel-leucena para produção de bovinos no semi-árido. Petrolina: EMBRAPA-CPATSA, 1995. 39p. (Circular técnica, 34).

HARGREAVES, J.N.; KERR, J.D. BOTANAL - A comprehensive sampling and computing procedure for estimating pasture yield and composition. II. Computacional package. St. Lucia: CSIRO, Division of Tropical Crops and Pastures, 1978. 88p. (Tropical agronomy technical memorandum, 9).

HAYDOCK, K.P.; SHAW, N.H. The comparative yield method for estimating dry matter yield of pasture. Australian Journal Experimental Agricultural Animal Husbandy, v.15, n.76, p.663-670, 1975.

HEADY, M.F.; TORELL, D.T. Forage preferences exhibited by sheep with esophagel fistulas. Journal Range Management, v.12, p.28-33, 1959.

HODGSON, J. Nomenclature and definitions in grazing studies. Grass Forrage Science, v.34, n.2, p.11-18, 1979.

EMPRESA PERNAMBUCANA DE PESQUISA AGROPECUÁRIA - Unidade de execução de pesquisa de Serra Talhada. Relatório das atividades do programa bovinos referente ao período de 1975/85. Serra Talhada-PE: 1986, 135p.

JONES, R.M.; HARGREAVES, J. N. G. Improvementes to the dry-weight-rank method for measuring botanical composition. Grass Forrage Science, v.4, n.2, p.181-189, 1979.
LIMA, G.F.C. Determinação de fitomassa aérea disponível ao acesso animal em caatinga pastejada - Região de Ouricuri - PE. Recife: Universidade Federal Rural de Pernambuco, 1984. 244p. Dissertação (Mestrado em Produção Animal) - Universidade Federal Rural de Pernambuco, 1984.

LIRA, M.A.; FERNANDES, A.P.M.; FARIAS, V.M. Utilização do pasto nativo e cultivado em recria e engorda de bovinos no semi-árido de Pernambuco. Revista Brasileira de Zootecnia, v.16, n.3, p.267-274, 1987.

MANNETJE, L.T; HAYDOCK, K.P. The dry-weight-rank method for the botanical analysis of pasture. Journal British Grassland Society, v.18, n.4, p.268-275,1963.

MARASCHIN, G.E. Sistema de pastejo. In: SIMPÓSIO SOBRE MANEJO DE PASTAGEM, 8., 1986, Piracicaba. Anais... Piracicaba: Escola Superior de Agricultura Luiz de Queiroz, 1986. p.261-290.

MERTENS, D.R. Creating a system for meeting the fiber requirements of dairy cows. Journal of Dairy Science, v.80, p.1463-1481, 1997

MESQUITA, R.C.M; ARAÚJO FILHO, J.A.; DIAS, M.L. Manejo de pastagem nativa: uma opção para o semi-árido nordestino. In: SIMPÓSIO NORDESTINO DE ALIMENTAÇÃO DE RUMINANTES, 2., 1988, Natal. Anais... Natal: EMPARN, 1988. p.124-140.

MESQUITA, R.C.M. Season feeding behaviour and forage selection by goats in cleared and thinned decidous woodlands in northeast, Brazil. Logan: Utah State University, 1985. 124p. Dissertation (Magister of Sciences) - Utah State University, 1985.

MINSON, D.J. Forage quality: assessing tre plant, animal complex. In: INTERNACIONAL GRASSLAND CONGRESS, 15., 1981, Kentuchy. Proceedings... Kentuchy; [sn] ,p.23-29.1981

MOURA, J.W.S. Disponibilidade e qualidade de pastos nativos e de capim Buffel (Cenchrus ciliaris, $L$.) diferido no semi-árido de Pernambuco. Recife: Universidade Federal Rural de Pernambuco, 1987. 159p. Dissertação (Mestrado em Produção Animal) - Universidade Federal Rural de Pernambuco, 1987.

NEIVA, J.N.M.; SANTOS, M.V.F. Manejo de pastagens cultivadas em regiões semi-áridos. In: CONGRESSO NORDESTINO DE PRODUÇÃO ANIMAL, 1. Fortaleza, 1998. Anais... Fortaleza: Sociedade Nordestina de Produção Animal, 1998. v.1 p.35-45.

OLIVEIRA, M.C. Capim-buffel: produção e manejo nas regiões secas do Nordeste. Petrolina: Embrapa - CPATSA, 1993. 18p (Circular Técnica, 27).

PETER, A.M.B. Composição botânica e química da dieta de bovinos, caprinos e ovinos em pastejo associado na caatinga nativa do semi-árido de Pernambuco. Recife: Universidade Federal Rural de Pernambuco, 1992. 95p. Dissertação (Mestrado em Produção Animal) - Universidade Federal Rural de Pernambuco, 1992.

RAMIREZ, R.G.; HUERTA J.M.; KAWAS.J.R. et al. Performance of lambs grazing in a buffelgrass (Cenchurs ciliaris) pasture and estimation of their maintenance energy requirement for growth. Small Ruminant Research, v.17, p.117-121, 1995.

REIS, R.A.; RODRIGUES, L.R.A.; PEREIRA, J.R.A.A. Suplementação como estratégia de manejo de pastagem. In: SIMPÓSIO SOBRE MANEJO DA PASTAGEM, 13., 1997, Piracicaba. Anais... Piracicaba: Fundação de Estudos Agrários Luiz de Queiroz, 1997. p.123-150. 
STATISTICAL ANALYSES SYSTEM - SAS. User's guide: version 6, 4.ed. Cary: 1997.

SILVA, D.J.; QUEIROZ, A.C. Análise de alimentos (métodos químicos e biológicos). Viçosa, MG: Universidade Federal de Viçosa, 2002. 235p.

SILVA, V.M. Composição botânica e protéica da pastagem e da dieta e desempenho de bovinos em caatinga nativa e manipulada. Ceará: Universidade Federal do Ceará, 1988. 111p. Dissertação (Mestrado em Zootecnia) - Universidade Federal do Ceará. 1988.

SILVA, C,C.M.S.; FARIA, C.M.B. Comportamento de leguminosas forrageiras tropicais sob adubação fosfatada em Petrolina. Pesquisa Agropecuária Brasileira, v.24, n.11, p.1319-323, 1989.

SILVA, C.M.M.S.; OLIVEIRA, M.C.; ALBUQUERQUE, S.G. Avaliação do desenvolvimento e da produtividade de treze cultivares de capim buffel. Pesquisa Agropecuária Brasileira, v.22. n.5, p.515-520, 1987.
SNIFFEN, C.J.; O'CONNOR, J.D.; Van SOEST, P.J. A net carbohydrate and protein system for evaluating cattle diets. II. Carbohydrate and protein availability. Journal of Animal Science, v.70, p.3562-3577,1992.

SOUZA, A.A.; ESPÍNDOLA, G.B. Efeito da suplementação com feno de leucena (leucaena Leucocephala (lam) de wet) durante a estação seca sobre o desenvolvimento ponderal de ovinos. Revista Brasileira de Zootecnia, v.28, n.6, p.1424-1429, 1999.

Recebido em: 14/10/03

Aceito em: 15/12/04 